\title{
Thomas L Petty's Lessons for the Respiratory Care Clinician of Today
}

\author{
David J Pierson MD FAARC
}

\author{
Introduction \\ Who Was Tom Petty? \\ Overview \\ Research and Original Observations \\ Career as an Educator \\ Publications \\ Efforts on Behalf of Patients \\ What Were His Most Important Contributions to Respiratory Care? \\ ARDS and Mechanical Ventilation in the Critically Ill \\ Comprehensive Care for Patients With COPD \\ Multidisciplinary, Patient-Focused Education and Training \\ What Was So Special About Tom Petty? \\ What Lessons Do Tom Petty's Life and Work Offer for Today and the \\ Future?
}

Because of the importance of his original contributions and their practical relevance today, Thomas $L$ Petty (1932-2009) was arguably the most important physician in the history of respiratory care. As much as any single individual, he was responsible for the concept of intensive and multidisciplinary respiratory care. In the 1960s and 1970s, he made key observations and introduced pioneering therapies in the ICU and in the home. He was the first to describe and name ARDS and to show how to use PEEP to treat life-threatening hypoxemia. He was one of the first anywhere to organize a pulmonary rehabilitation program and to show the beneficial effects of long-term oxygen therapy in COPD. Dr Petty emphasized the importance of practical, hands-on respiratory care education for both physicians and non-physicians using a collaborative team approach. He targeted educational activities and practical resources specifically to patients, and he showed how researchers and clinicians could interact responsibly with innovators in industry to the benefit of both. His life and career provide 6 important lessons for respiratory clinicians today and in the future: (1) whatever their roles, RTs and other clinicians in this field need to be experts in its core areas, such as mechanical ventilation, ARDS, and COPD; (2) respiratory care is a team activity: every member is important, and all the members need to communicate well and work together; (3) education needs to be targeted to those in the best position to benefit the patient, including primary care providers and family members; (4) everyone in the field needs to understand the important role of the respiratory care industry and to deal with it responsibly; (5) it must never be forgotten that it is all about the patient; and (6) respiratory care should be exciting and fun. Key words: respiratory care; acute respiratory failure; mechanical ventilation; ARDS; PEEP; COPD; long-term oxygen therapy; pulmonary rehabilitation; education; patients; history. [Respir Care 2014;59(8):1287-1301. (C) 2014 Daedalus Enterprises] 


\section{Introduction}

Thomas L Petty MD (Fig. 1) died at age 76 on December 12, 2009.1,2 Acclaimed as "the most outstanding chest physician of his generation,"3 Dr Petty was arguably also the most important physician in the history of respiratory care.

The term respiratory care has several meanings, depending on where and by whom it is used. ${ }^{4}$ In the broadest sense, respiratory care is a subject area within health care that deals with the principles, skills, apparatus, and therapies used in evaluating and managing disorders affecting the respiratory system. Respiratory care as a subject area thus includes patient assessment, airway management, support or augmentation of oxygenation and ventilation, aerosol therapy, chest physical therapy, pulmonary rehabilitation, and numerous other modalities, all applied in the context of an understanding of respiratory physiology and how it becomes deranged by illness. In different parts of the world, these components are dealt with by different health professions or combinations of professions, which include pulmonologists, anesthesiologists, intensivists, physiatrists, nurses, physical therapists, and others.

Primarily in the United States, respiratory care also refers to a specific profession whose members (respiratory therapists [RTs]) work in a wide array of clinical contexts under medical direction and in collaboration with other health professionals. ${ }^{4}$ This workforce now includes several classes of RT training program graduates who entered the field after Dr Petty died and may be unfamiliar with his contributions to their field or even with his name. The purpose of this article, developed from the first annual Thomas L Petty MD Memorial Lecture of the American Association for Respiratory Care (AARC), is to remedy this situation. It first chronicles Dr Petty's long and astoundingly productive career as a clinician, researcher, and educator, emphasizing his most important achievements in respiratory care. It then attempts to explain why this man was so special and his contributions so important to this field and to the RT profession and finishes by listing what

Dr Pierson is affiliated with the Division of Pulmonary and Critical Care Medicine, Department of Medicine, University of Washington, and with Harborview Medical Center, Seattle, Washington.

Dr Pierson presented a version of this paper as the First Thomas L Petty MD Memorial Lecture at the 59th AARC Congress, held November 16-19, 2013, in Anaheim, California.

Correspondence: David J Pierson MD FAARC, Pulmonary and Critical Care Medicine, Harborview Medical Center, Box 359762, 325 Ninth Avenue, Seattle, WA 98104. E-mail: djp@u.washington.edu.

DOI: $10.4187 /$ respcare. 03495

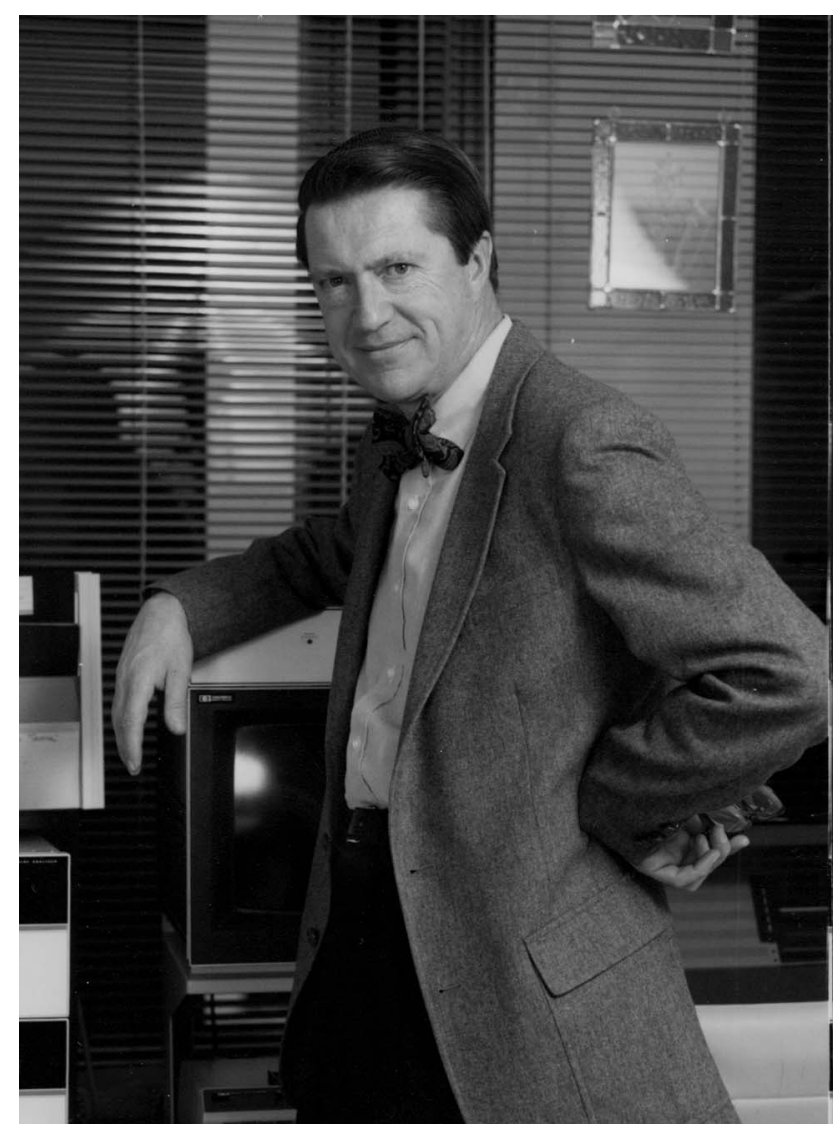

Fig. 1. Thomas L Petty MD in his office at the University of Colorado Medical Center. Courtesy Louise $\mathrm{M}$ Nett.

I consider to be the key lessons he has left for today's clinicians and those in future generations.

\section{Who Was Tom Petty?}

When I developed an interest in pulmonary medicine as a medical resident at Johns Hopkins, I went to see Dr Solbert Permutt, a senior professor there and one of the leading pulmonary physiologists of his generation, for career advice. I explained that I was not interested in laboratory research but wanted to learn how to take the best possible care of patients with lung disease. Dr Permutt told me there was only one place I should consider training, the University of Colorado, where there was a junior faculty member named Tom Petty who was changing the face of clinical pulmonary medicine. Two years later, I was fortunate enough to become one of Dr Petty's fellows and eventually also his colleague and friend. Dr Permutt's advice proved to be right in every way.

When I arrived in Denver in the summer of 1971 to complete my internal medicine residency, Dr Petty had just been named head of the pulmonary division. By that time, he had already established a multidisciplinary system 
for respiratory care in both hospital and home settings, described and named the adult (acute) respiratory distress syndrome (ARDS), demonstrated the effect of PEEP on arterial oxygenation, shown the beneficial effects of longterm oxygen therapy (LTOT) on mortality and quality of life in COPD, and established one of the world's first pulmonary rehabilitation programs. It was a dynamic, exhilarating environment in which to train in the emerging discipline of pulmonary and critical care medicine, an environment that had already introduced concepts and therapies with profound impact on clinical practice and our understanding of disease, as well as on the lives of patients who would one day number in the millions.

\section{Overview}

Thomas L Petty was born in Boulder, Colorado, on December 24, 1932. Attending the University of Colorado in his home town, he earned a bachelor's degree (Phi Beta Kappa) in 1955 and then received his MD degree from the University's medical school in Denver, graduating first in his class. Planning to become a family physician, he took a year of rotating internship at Philadelphia General Hospital and then was a junior assistant resident in internal medicine at the University of Michigan in 1959-1960. ${ }^{1}$

Although he would later be selected as the outstanding resident in his class, also during that year in Michigan, a revealing event occurred that hinted at Dr Petty's future accomplishments as well as at his characteristic out-ofthe-box approach to problem solving. Rotating on the hematology service and having admitted a patient who carried the diagnosis of polycythemia vera, he became convinced that this patient's elevated hematocrit was not due to that primary blood disorder but was instead a compensatory physiological response to chronic hypoxemia. To demonstrate this, he drew a sample of the patient's arterial blood at the bedside and convinced a technician in the cardiology research laboratory to measure its oxygen content and capacity, calculating oxyhemoglobin saturation and documenting the presence of severe hypoxemia. ${ }^{5}$ Arterial puncture was not a common diagnostic procedure in those days, and it was the province of the cardiologists, who admitted patients to their service specifically for this procedure. Despite its success in revealing the correct diagnosis (and the absence of any adverse effects for the patient), after Dr Petty described the procedure and its results during the next morning's rounds, he was called to the department chief's office, reprimanded, and suspended from the residency program. Although he was reinstated a few days later, this episode says a lot about his assertiveness and creativity, as well as about the status of physiologically based respiratory diagnostic methods in 1959 .

The next year, Dr Petty returned to Denver and to the University of Colorado, where he would remain for nearly
50 years. He completed his medicine residency in 19601962 and then a pulmonary fellowship year under Dr Roger Mitchell, head of that division. After an additional year as medical chief resident, he was appointed as a junior faculty member in 1964 . The medical center had recently set up a respiratory care unit, and Dr Petty became its chief in 1965. In 1968, he was placed in charge of the pulmonary fellowship training program, and in 1971, at age 38, he replaced Dr Mitchell as division head. Promoted to full professor 3 years later, he retained that title until his death in 2009. Dr Petty directed the fellowship training program until 1983 and the renamed Division of Pulmonary Sciences and Critical Care Medicine until 1985.

Charismatic, with boundless energy and the ability to stimulate and inspire those around him, throughout his long career, Dr Petty excelled at collaboration and the bringing together of people with diverse skills and perspectives to attack challenging problems, whether the latter be a better understanding of disease, new or more effective treatments for patients, or real-world obstacles to the application of these treatments. His work brought international attention, and he developed friendships and working relationships with many leading researchers and clinicians throughout the world. An influential contributor to numerous governmental organizations and professional societies, he served on and/or chaired numerous committees of the American Board of Internal Medicine, the American Thoracic Society (ATS), and the American College of Chest Physicians (ACCP), serving as ACCP president as well as chair of its Board of Regents.

During a long and continuously productive career, Dr Petty received many recognitions, honors, and awards, too many by far to list comprehensively here. Pertinent to the context of this article, he was one of the first physicians elected to fellowship in the AARC. He received its Forrest M Bird Award in 1986 and the Dr Charles H Hudson Award for Cardiopulmonary Public Health in 2004 and was the 2003 recipient of the Jimmy A Young Medal, the Association's highest honor. Dr Petty held adjunct or honorary professorships at several medical centers and universities across the United States. In 1995, he received the ATS's Distinguished Achievement Award. Bestowing on him the exceptional designation of Master ACCP in 1995, the College and the CHEST Foundation created the Thomas L Petty Endowment in Lung Research in his honor in 2007.

\section{Research and Original Observations}

Dr Petty's contributions to the management of acute respiratory failure and COPD established the very core of respiratory care as it exists today. As discussed in greater detail below, I think that his most important achievements in research lie in clinical aspects of those 2 conditions, 
although he also made noteworthy original contributions in a wide variety of other areas of medicine, from observations on basic mechanisms to administrative and organizational matters.

Along with his clinical investigations related to COPD, he and his colleagues carried out a long series of studies dealing with the pathology of emphysema and its correlations with physiology. He conducted several early studies related to drug therapy of tuberculosis and the long-term sequelae of this disease, and late in his career, he became interested in lung cancer (particularly its prevention and early detection) and was a co-investigator on several published studies in this area. With fellows and other trainees, he co-authored clinical reviews on pulmonary manifestations of a wide variety of diseases, plus numerous case series and individual case reports. He also published original investigations involving new devices, including ventilators, monitors, and equipment for oxygen and aerosol therapy, and clinical evaluations of several new drugs and drug combinations. ${ }^{6}$

\section{Career as an Educator}

By the time Dr Petty became division head, he was already widely respected as an educator in the field that would shortly become known as pulmonary and critical care medicine. As I had discovered in my own search for the best possible fellowship training, the 4 first-year positions in his program were as sought after as any training positions in the country, in any field, particularly for those seeking clinically focused (as opposed to laboratory-based) academic training. Dr Petty was the founding chairman of the organization now known as the Association of Pulmonary and Critical Care Medicine Program Directors (http:// www.apccmpd.org, Accessed May 19, 2014). As director of the University of Colorado's program, he personally trained approximately 100 fellows, and by 2010, these included 5 department chairs, 9 division heads, and 26 full professors of medicine; 4 of his trainees had served as presidents of the ATS, and 2 had received that Society's prestigious Trudeau Medal. ${ }^{1}$

Dr Petty was unsurpassed at furthering and promoting the careers of his trainees. Long before there were job fairs and networking systems for finding academic positions, he brought his fellows to ATS, ACCP, and other important conferences and introduced them to the right people. At one such conference, he introduced me to Philip Kittredge, this Journal's editor in the 1970s, and encouraged me in submitting my first article to appear in its pages. Dr Petty often received speaking invitations that his busy schedule would not permit him to accept, and when this happened, he recommended his fellows and junior colleagues instead, thus giving them important exposure and aiding their careers. I personally benefitted from this aspect of Dr Petty's efforts, as did many of the program's distinguished alumni referred to above.

Because of its growing reputation in both critical care and long-term COPD management, under Dr Petty, the division was host to a continuous stream of international visitors, many of them prominent clinicians and investigators in their respective countries. Both in the units and in social gatherings after work, exposure to the diversity of expertise and culture brought to Denver by these visitors played an important role in the training experience there.

\section{Publications}

A man of limitless energy who never slept more than a few hours each night, Dr Petty typically arrived at his office by $5 \mathrm{Am}$ and spent 2 or 3 hours writing before rounds. ${ }^{1,5}$ The result of this lifelong work ethic was a truly prodigious output of publications: his bibliography 6 includes 941 individual publications, 409 of them listed in PubMed, with the latter appearing in 94 different journals! From 1966 through 2006, he produced at least 4 PubMedcited publications every year (Fig. 2).

Dr Petty served on the editorial boards of most of the scientific journals of his day that were relevant to respiratory care: his curriculum vitae lists 17 in all. ${ }^{6} \mathrm{He}$ was co-editor-in-chief of Seminars in Respiratory and Critical Care Medicine, a senior editor for Chest, and an associate editor of the American Review of Respiratory Disease, now the American Journal of Respiratory and Critical Care Medicine. His bibliography lists 45 books that he wrote, co-authored, or edited, including subsequent editions, between 1967 and 2006. His Intensive and Rehabilitative Respiratory Care, ${ }^{7}$ published in 1971 with 2 subsequent editions, was the first widely circulated book to deal with both acute and long-term respiratory care from a practical, multidisciplinary perspective. Among numerous others, he also edited important works on pulmonary diagnostic techniques, ${ }^{8} \mathrm{COPD},{ }^{9,10}$ and pulmonary rehabilitation. ${ }^{11}$

The Aspen Lung Conference was founded in 1957.5,12,13 Although the initial series of these conferences, supported by the American Lung Association, was scheduled to be discontinued after 1964, Dr Petty proposed another conference the following year to be devoted to COPD as a treatable condition, to my knowledge the first attempt anywhere to approach the subject from that perspective. ${ }^{5}$ The 1965 conference was so successful ${ }^{14}$ that Dr Petty resolved to keep the series going. Charged with raising the money to allow the conferences to continue, he obtained funds from the federal government and also subsequently from industry, supporting their continuation for the next several years. ${ }^{5,13}$ Finally, in 1978, he established the Aspen Lung Conference Endowment Fund, which continues to host the conference. In recognition of both his scientific and logis- 


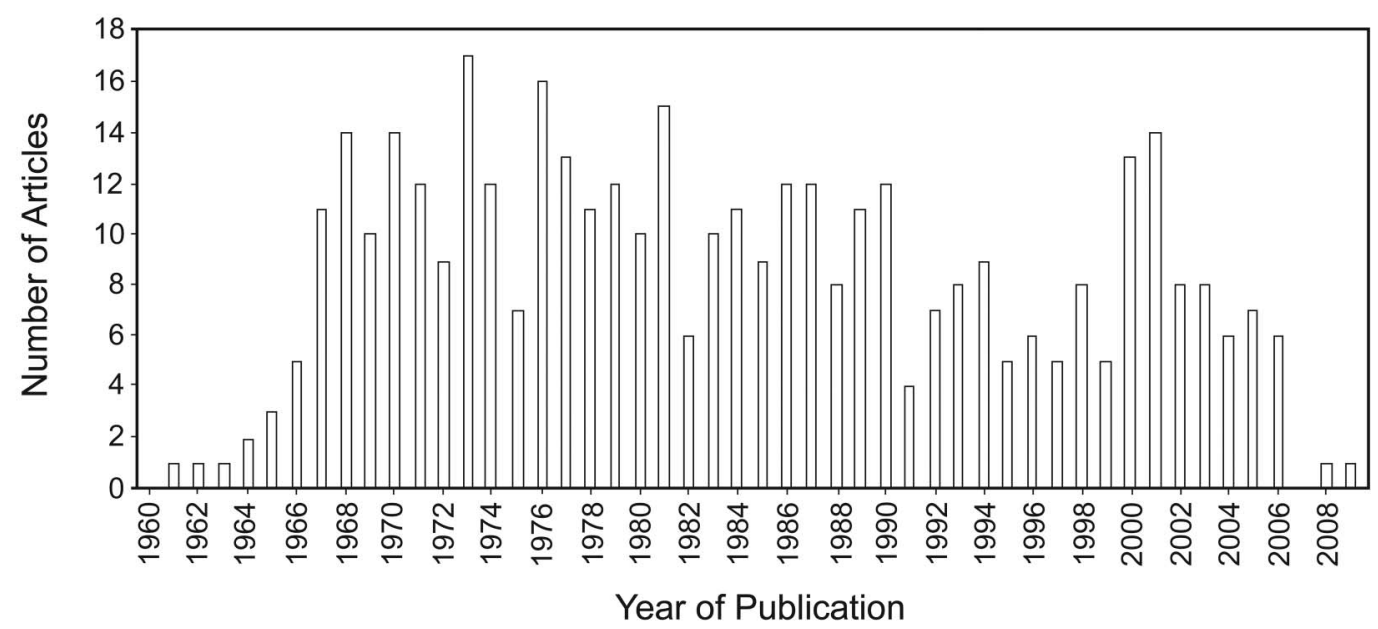

Fig. 2. During his long career, Thomas L Petty MD published 4 or more PubMed-cited articles each year for 41 consecutive years.

tic efforts on behalf of the conference, the latter was renamed the Thomas L Petty Aspen Lung Conference in 1989. The proceedings of every conference throughout its long and distinguished history have been published, ${ }^{12}$ as a lasting legacy of Dr Petty's vital contributions to one of the world's premier research conferences.

\section{Efforts on Behalf of Patients}

In addition to his many scientific publications and contributions to medical education, Dr Petty made unique and unparalleled contributions to the direct care of patients. In 1994, having secured funds from the pharmaceutical industry and other sources, he established the Snowdrift Pulmonary Conference, a nonprofit corporation for the purpose of developing educational materials for patients and also for frontline health professionals, especially primary care physicians. ${ }^{15}$ To this purpose, Dr Petty assembled a small group of academic and practicing pulmonary physicians yearly at a fishing lodge in the Northwest Territories, Canada, to rough out a monograph dealing with some aspect of caring for patients with chronic lung disease. After editing by all the contributors, the books were distributed to practicing physicians through the Snowdrift organization. The first of 10 of these Frontline monographs (on the practical management of COPD) was published in 1996. ${ }^{16}$ Five of them, including Frontline Advice for COPD Patients, continue to be available free via the Snowdrift Conference's web site. ${ }^{15}$

In 1996, Dr Petty founded the National Lung Health Education Program, "a new healthcare initiative designed to increase awareness of Chronic Obstructive Pulmonary Disease (COPD) among the public and health care professionals and to encourage the use of simple spirometry to make an earlier diagnosis and monitor ongoing treatment" (http://www.nlhep.org, Accessed May 19, 2014). He was also instrumental in developing the Colorado COPD Connection, now known as the Colorado Lung Health Connection, through which he established an annual conference for patients, today known as the Thomas L Petty MD Moving Mountains Lung Health Conference. ${ }^{17}$ Run like a continuing education conference for health professionals but set up expressly for patients and their caregivers, this meeting offers presentations and workshops on clinical topics but also on equipment, reimbursement issues, and social concerns, given by experts from a variety of disciplines.

Dr Petty published several books targeted to patients with COPD and other chronic lung diseases. The first of these, one of the first ever to be directed at a lay readership, was For Those Who Live and Breathe with Emphysema and Chronic Bronchitis, co-authored with Louise M Nett RN RRT FAARC and published in 1967. ${ }^{18}$ This book appeared in several updated versions over the next 3 decades. ${ }^{19-22}$ Another successful publication for patients was his Adventures of an Oxy-Phile, published in 2004 by the AARC, which included not only his own observations but also chapters by patients describing their experiences with LTOT. ${ }^{23}$ A revision left unfinished at the time of Dr Petty's death was subsequently completed by his colleagues Robert W McCoy RRT FAARC, Louise M Nett RN RRT FAARC, and Kay Bowen. ${ }^{24}$ This last among Dr Petty's distinguished series of books is available as a free PDF download $^{25}$ and also as an audio book read by Patrick $\mathbf{J}$ Dunne MEd RRT FAARC at the AARC's web site. ${ }^{26}$

Over a period of 28 years, Dr Petty wrote an extensive series of letters offering practical advice for patients with chronic pulmonary disease. Many of these "Letters from Tom," originally circulated in the monthly newsletters of patient organizations, remain available on the web site of 
the Pulmonary Education and Research Foundation. ${ }^{27}$ In the last 15 years of his life, he also collaborated closely with the AARC on resources for patients, prominently via the Ask Dr. Tom feature on its Your Lung Health web site. ${ }^{28}$

\section{What Were His Most Important Contributions to Respiratory Care?}

Respiratory care as we know it today, from critical care ventilators managed by knowledgeable practitioners using evidence-based protocols guided by arterial blood gases and an array of other monitors in well-equipped ICUs to long-term care in patients' homes and other settings that relies on a diversity of equipment, procedures, and personnel, simply did not exist when Dr Petty began working in this field. Both the physiologic understanding of acute respiratory failure and the means for assessing and supporting patients who developed it were basically unavailable, even in major medical centers. To administer supplemental oxygen to patients with chronic lung disease was believed to deprive them of the drive to breathe and was considered a grave threat for $\mathrm{CO}_{2}$ narcosis and death, and as a result, it tended to be used sparingly or withheld altogether. Outside the hospital or doctor's office, oxygen was considered so dangerous that some of the early patients prescribed ambulatory oxygen for COPD were denied access to restaurants or public transportation for fear of explosions and fire. By the late 1960s, arterial blood gas machines were beginning to be used, but even when they were available, physicians in most institutions had to draw the specimens and run them themselves, given that respiratory therapy departments and clinical laboratories had not yet evolved to support this activity.

With this as background, I would like to discuss further the 3 areas in which I consider Dr Petty's contributions to be most important in shaping respiratory care as we know it today. These are respiratory intensive care (his term), especially ARDS, PEEP, and the ventilatory support of critically ill patients with acute respiratory failure; the comprehensive management of patients with COPD, particularly LTOT; and patient-focused education for everyone involved, from pulmonologists and RTs to primary care providers to the patients themselves. Dr Petty did important work in other areas, some of which I have alluded to previously, but I believe it is in these 3 aspects of respiratory care, which make up the very core of the field, that his contributions are most important today and will remain so for future generations.

\section{ARDS and Mechanical Ventilation in the Critically III}

Dr Petty's achievements in this area were greatly facilitated by his close working relationship with the thoracic

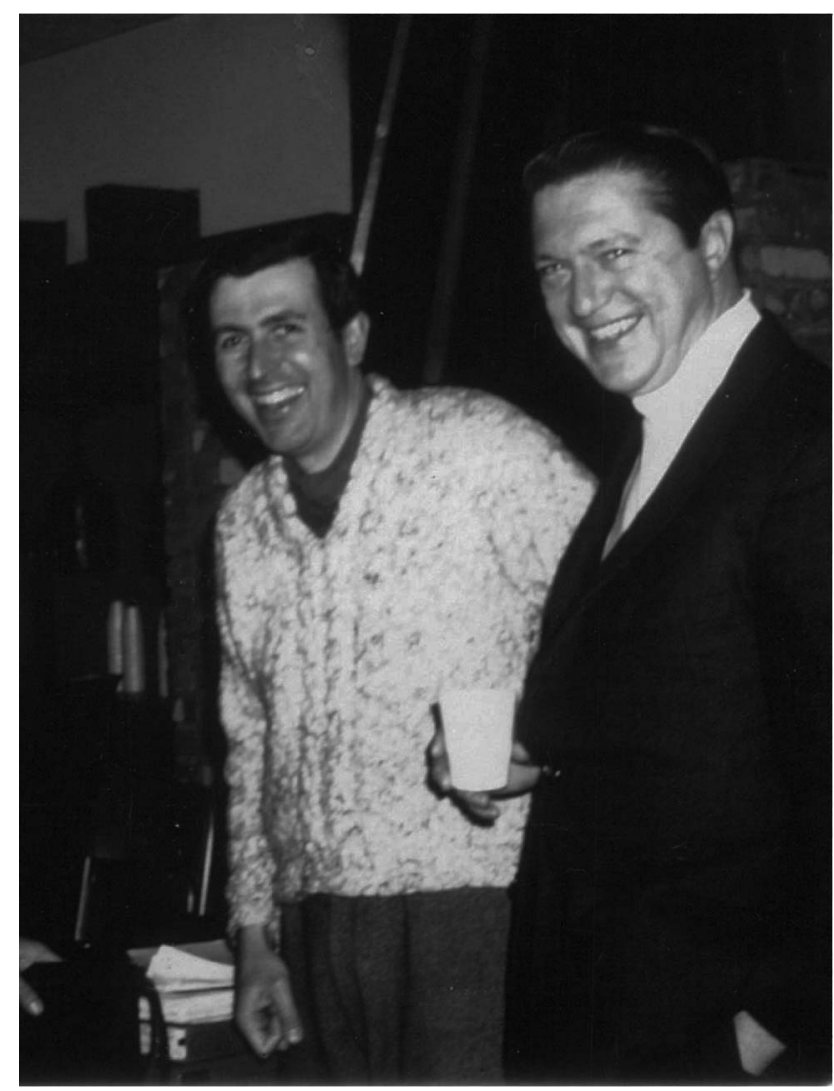

Fig. 3. Thomas L Petty MD (right) and his surgical colleague David G Ashbaugh MD (left) in the late 1960s. Courtesy Louise M Nett.

surgeon David G Ashbaugh, a type of collaboration far from usual in the hospital culture of the time (Fig. 3). Exact contemporaries, they were chief residents in the medicine and surgery services, respectively, of the University of Colorado Medical Center in 1963-1964. Both joined the faculty in the summer of 1964 .

In the fall of 1964, a young man was admitted to the ICU with multiple injuries following a motor vehicle crash, and he soon developed respiratory distress, severe hypoxemia, and diffuse bilateral infiltrates on chest radiograph. ${ }^{5,29}$ With increasingly stiff lungs, adequate ventilation and oxygenation of this patient could not be achieved with the pressure-targeted Bird Mark VII ventilator. The hospital's anesthesia department had an unused 1954 Engström constant-minute-volume ventilator, purchased originally for research, and Dr Ashbaugh retrieved this machine from storage in an attempt to support his progressively deteriorating patient. The Engström's greater pressure capability permitted more effective ventilation. It also had a threshold resistor in the expiratory circuit that could be used to produce expiratory retard (initially referred to as continuous positive-pressure breathing and subsequently as PEEP by the Colorado group), and although neither Dr Ashbaugh nor Dr Petty had any experience with this, when it 
Table 1. Changes in Oxygenation With Sequential Changes in PEEP in a Patient With Severe Hypoxic Respiratory Failure Complicating Hemorrhagic Pancreatitis

\begin{tabular}{lrrrr}
\hline \hline PEEP $\left(\mathrm{cm} \mathrm{H}_{2} \mathrm{O}\right)$ & 0 & 10 & 0 & 10 \\
$\mathrm{P}_{\mathrm{aO}_{2}}(\mathrm{~mm} \mathrm{Hg})$ at $\mathrm{F}_{\mathrm{IO}_{2}} 1.0$ & 44 & 125 & 45 & 135 \\
\cline { 1 - 1 } From Reference 29. & & & & \\
\hline
\end{tabular}

was applied, there was a prompt increase in the patient's arterial oxygen saturation. The patient died 3 days later, however, and at autopsy, his lungs were dense with extensive "congestive atelectasis." 5

The following year, a woman was admitted to the medical service with hemorrhagic pancreatitis, and she developed the same set of clinical findings as the earlier trauma patient: respiratory distress, severe hypoxemia, bilateral infiltrates, and increasingly stiff lungs. Dr Petty ventilated her successfully with the Engström ventilator, once again observing improved oxygenation with the application of PEEP. He demonstrated that the latter was not coincidental by the sequence of settings shown in Table $1,{ }^{5}$ measuring the changes in $\mathrm{P}_{\mathrm{aO}}$ on the blood gas machine in his laboratory. This patient subsequently died after several days of refractory hypoxemia and hypercapnia, and postmortem examination showed "heavy lungs, alveolar debris, and hyaline membrane formation." 29

Discussing the similar presentations of these 2 patients despite the different initial circumstances, Drs Petty and Ashbaugh concluded that their features might have enough in common to represent a distinct syndrome. They considered the improved oxygenation with PEEP to be important and used it systematically in several subsequent patients. Of 272 patients ventilated for acute respiratory failure since the respiratory care unit opened, 12 showed the characteristics of this syndrome..$^{29}$ The first patient to survive the syndrome with management that included the use of PEEP was a 15-year-old boy with hemorrhagic shock following a motor vehicle crash, and although 5 of Drs Ashbaugh and Petty's first 7 patients pre-PEEP had died, 10 of 14 similar patients managed with PEEP survived.

Drs Ashbaugh and Petty, along with 2 of Dr Petty's fellows, prepared a manuscript describing this new syndrome, which they termed "acute respiratory distress in adults," acknowledging its similarities to the previously described infant respiratory distress syndrome. They submitted their paper summarizing the clinical features and management of the initial 12 patients to the New England Journal of Medicine, which promptly rejected it as documentation of inappropriate and dangerous ventilator management. ${ }^{5}$ A revision submitted to the Journal of the American Medical Association was similarly rejected, as was a subsequent version sent to the American Journal of Surgery. Somewhat in desperation, the authors finally submit-

\section{ACUTE RESPIRATORY DISTRESS IN ADULTS}

David G. Ashbaugh M.D. Ohio State

ASSISTANT PROFESSOR OF SURGERY

D. Boyd Bigelow M.D. Colorado

ASSISTANT IN MEDICINE AND AMERICAN THORACIC SOCIETY-NATIONAI TUBERCULOSIS ASSOCIATION FELLOW IN PULMONARY DISEASE

Thomas L. Petty

M.D. Colorado

ASSISTANT PROFESSOR OF MEDICINE

BERNARD E. LEVINE

M.D. Michigan

AMERICAN THORACIC SOCIETY-NATIONAL TUBERCULOSIS ASSOCIATION FELLOW IN PULMONARY DISEASE*

From the Departments of Surgery and Medicine, University of Colorado Medical Center, Denver, Colorado, U.S.A.

Summary The respiratory-distress syndrome in 12 patients was manifested by acute onset of tachypnœa, hypoxæmia, and loss of compliance after a variety of stimuli; the syndrome did not respond to usual and ordinary methods of respiratory therapy. The clinical and pathological features closely resembled those seen in infants with respiratory distress and to conditions in congestive atelectasis and postperfusion lung. The theoretical relationship of this syndrome to alveolar surface active agent is postulated. Positive end-expiratory pressure was most helpful in combating atelectasis and hypoxæmia. Corticosteroids appeared to have value in the treatment of patients with fat-embolism and possibly viral pneumonia.

Fig. 4. Title, author information, and abstract from the 1967 Lancet article originally describing ARDS. From Reference 30.

ted the manuscript to The Lancet. There, it was quickly accepted for publication and appeared as a lead article in the summer of 1967 (Fig. 4). ${ }^{30}$ Subsequent decades have shown this paper to be one of the seminal contributions to all of critical care medicine. It is certainly one of the most referenced, having been cited by other indexed articles 1,630 times as of April 11, 2014 (http://thomsonreuters. com/thomson-reuters-web-of-science, Accessed May 19, 2014).

Drs Petty and Ashbaugh soon became internationally known for ARDS and PEEP, having published several additional widely read and influential articles on these topics. ${ }^{31,32}$ One of their first publications on ARDS and its management, co-authored with Louise Nett, appeared in Respiratory Care. ${ }^{33}$ Dr Petty and his colleagues subsequently performed one of the first studies on the sequelae of ARDS among its survivors, documenting that most of them returned to normal functional status. ${ }^{34}$ Later, his group was also among the first to document the incidence and timing of ARDS in patients with specific predisposing factors. ${ }^{35}$ 


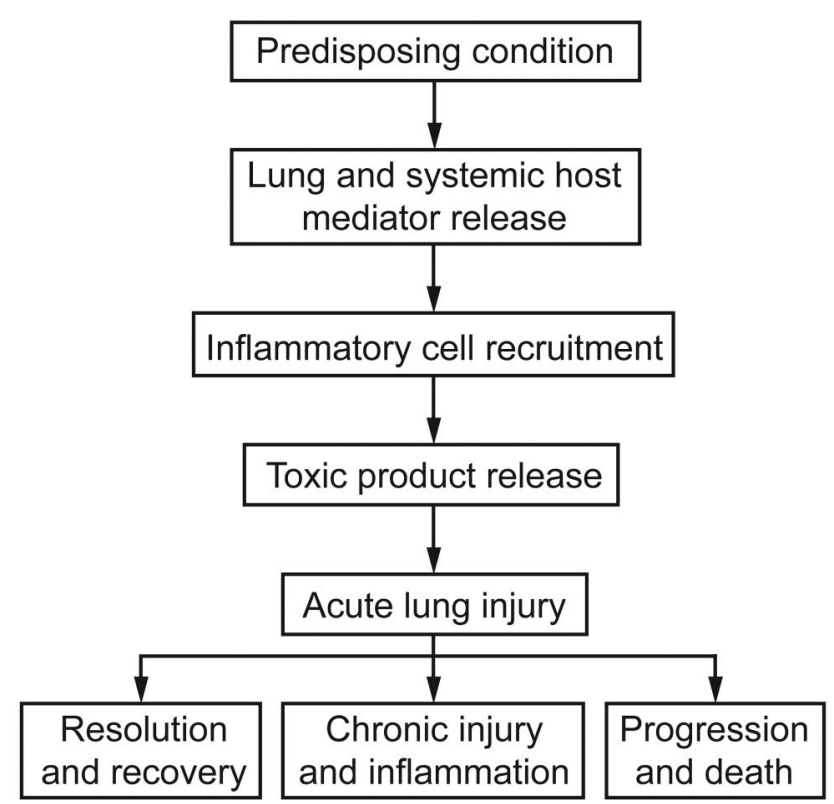

Fig. 5. A simplified depiction of the pathogenesis of ARDS and the possible outcomes once it develops, as currently understood. This 21 st century schema is entirely consistent with the concepts introduced by Drs Ashbaugh and Petty and their colleagues nearly 50 years ago in their initial description of the syndrome. Recent research has extended and refined the relationships in this diagram (eg, by the finding that pulmonary injury can in turn exacerbate systemic injury), but the original concepts remain valid.

Although our understanding of the pathophysiology of ARDS has been extended and refined a great deal since the landmark paper in The Lancet nearly 50 years ago, the salient features of the syndrome and most of the key concepts of its pathogenesis were described or proposed by $\mathrm{Dr}$ Petty in his early publications (Fig. 5). He wrote in a 1971 review that "It appears from our clinical experience of over 40 cases . . that the ARDS is basically a nonspecific response to a variety of pulmonary injuries." 32 Whether the predisposing injury was to the lungs and airways (as with severe pneumonia or near drowning) or affected parts of the body remote from the lungs (as with multiple trauma or hemorrhagic pancreatitis), Dr Petty and his colleagues postulated that circulating mediator substances from injured tissue recruited inflammatory cells to the lungs and that the subsequent release of toxic substances led to the histologic and clinical features comprising ARDS. They commented in the 1971 review that "the ultimate outcome is dependent upon three factors: the degree of original injury, the effectiveness of respiratory support, and the prevention of further pulmonary injury." 32 This has proven to be the case.

Dr Petty pioneered other aspects of respiratory intensive care that have become central to today's practice. He and his trainees carried out the first large prospective studies of adverse effects associated with mechanical ventilation ${ }^{36}$ and the use of artificial airways in patients with acute respiratory failure. ${ }^{37}$ Although the results of these observational studies were criticized by some as evidence of substandard patient care, subsequent research in both areas has repeatedly corroborated their findings, emphasizing the previously underappreciated frequency and morbidity of these complications. The Denver group also studied weaning from mechanical ventilation in a systematic, physiological fashion. ${ }^{38}$ Under Dr Petty's tutelage, Steven A Sahn and S Lakshminarayan, 2 of his fellows, performed the first-ever prospective evaluation of how successful ventilator discontinuation might be predicted using simple bedside measurements while the patient is still receiving full ventilatory support. ${ }^{39}$ Only one or two clinically useful additions to the weaning parameters developed from that study have emerged in the last 40 years, and they remain the basis of assessment for weaning, worldwide, to this day.

The concepts of a special area in the hospital to care for its most severely ill patients and of a cadre of clinicians drawn from multiple health disciplines with special expertise in such care were unknown in most institutions in the mid-1960s. As director of one of the first of such units in North America to focus on patients with acute respiratory failure, Dr Petty published several reports of its organization and initial results. ${ }^{40-42} \mathrm{He}$ subsequently chaired an ACCP task force to establish guidelines for such units. ${ }^{43}$ The study from his unit of over 18,000 consecutive patients who were ventilated for at least 24 hours for acute respiratory failure was among the first (and at the time, the largest) to report comprehensive data on survival and other clinical outcomes in respiratory care. ${ }^{44}$

In recent years, many investigators have presented evidence of the deleterious effects on both neuromuscular and psychological functions of immobility and excessive sedation in patients with acute respiratory failure. Dr Petty was well aware of these hazards more than 40 years ago and was an outspoken early advocate of keeping patients awake and of getting them out of bed during mechanical ventilation, ${ }^{45}$ continuing this advocacy into the present era. ${ }^{46} \mathrm{He}$ was notorious both among his own staff and on the lecture circuit for promoting ambulation once the initial insult precipitating critical illness had been stabilized. Generations of clinicians became familiar with his admonition to "bag "em and drag "em" around the ICU, with a nurse on one side of the patient and an RT on the other.

The following statements from his book Intensive and Rehabilitative Respiratory Care are very much in keeping with what we consider best practice today. ${ }^{47}$

Maintaining the function of the musculoskeletal system is a prime concern with any acutely ill patient. Even though patients with respiratory failure are often surrounded by complex equipment, [the cli- 
nician] should not forget the time-honored principles of exercise ... and ambulation if this is at all possible.

For patients who are able, sitting upright in a chair should begin as soon as possible. With a little assistance, the patient can be helped out of bed without disconnecting the respirator.

Even patients with severe respiratory insufficiency can be successfully ambulated when ventilation is augmented with a self-inflating bag with added oxygen.

\section{Comprehensive Care for Patients With COPD}

Following the success of the 1965 Aspen Lung Conference on COPD as a treatable condition, which Dr Petty chaired, ${ }^{13}$ he applied to the United States Chronic Respiratory Disease Control Program for a contract to organize a multidisciplinary pulmonary rehabilitation program as a formal demonstration project. ${ }^{5}$ This application was successful, and the country's first such project was established at the University of Colorado in 1966.48 Dr Petty assembled a team consisting initially of 2 home-care nurses, a social worker, and a pulmonary function technician; 2 of his pulmonary fellows later joined the group. ${ }^{5}$ One-hundred eighty-two consecutive patients with COPD, many of them survivors of acute respiratory failure managed with mechanical ventilation, were enrolled. ${ }^{5}$ Over the next few years, the group documented a number of clinical and quality-of-life improvements in these subjects, ${ }^{48-50}$ including reduced need for hospitalization ${ }^{51}$ and, in some cases, return to gainful employment. ${ }^{52}$ To a substantial degree, Dr Petty's pioneering pulmonary rehabilitation program established the foundations for the present state of the art in this core component of respiratory care. ${ }^{53}$

From the beginning, LTOT was a key aspect of Dr Petty's approach to COPD management, stimulated in part by the greater prevalence of chronic hypoxemia at Denver's 5,280-foot elevation. Although it was not yet a common clinical procedure, Dr Petty demonstrated the simplicity and safety with which arterial puncture could be performed and the status of arterial oxygenation determined in patients. ${ }^{54} \mathrm{He}$ and his colleagues showed in 6 patients with COPD that LTOT could reduce pulmonary arterial pressures and secondary erythrocytosis. ${ }^{55}$ Along with these benefits came improvement in clinical cor pulmonale, better functional status, and reduced hospitalizations for many patients. In lectures, Dr Petty demonstrated this last benefit dramatically with a photograph of 2 markedly different stacks of paper, showing how the extensive in-patient hospital record of one of his early patients was dramatically reduced during the year after she was begun on LTOT. ${ }^{56}$

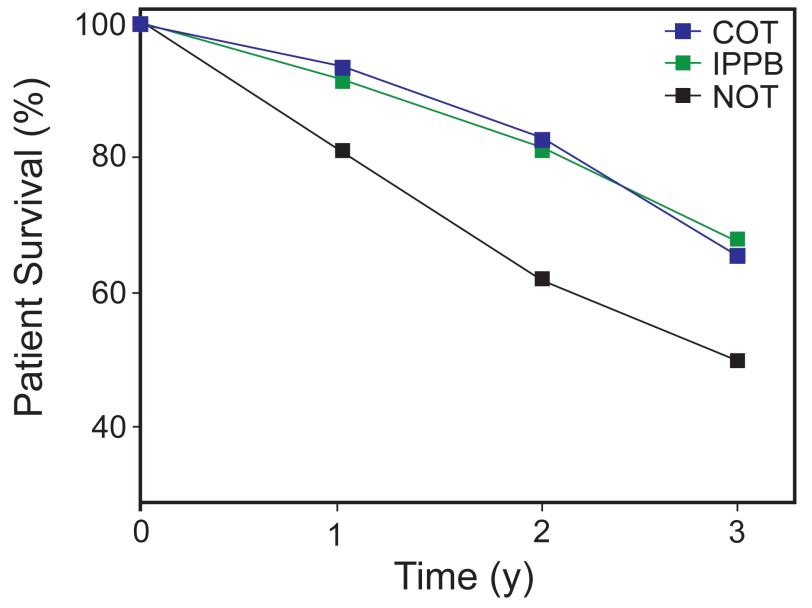

Fig. 6. Survival among subjects with COPD, under age 65 and with similar pulmonary function impairment, in the Nocturnal Oxygen Therapy Trial (NOTT) ${ }^{58}$ and Intermittent Positive Pressure Breathing (IPPB) studies. ${ }^{62}$ NOTT subjects (blue and black lines) had chronic hypoxemia and used oxygen either continuously (COT) or only at night (NOT); IPPB study subjects (green line) had the same severity of obstruction but were not hypoxemic and did not use oxygen. Displaying the survival curves in this way supports Dr Petty's concept that, for any given severity of obstruction, continuous oxygen therapy restores the overall prognosis in hypoxemic COPD patients to what it would be if they were not hypoxemic. Data from Reference 62.

It seemed obvious to Dr Petty that LTOT was also lifesaving for patients with cor pulmonale and other manifestations of chronic hypoxemia complicating COPD. Of the rehabilitation program's initial 182 patients, 53 were managed with LTOT, of whom 33 received it 24 hours a day for at least 1 month. Compared with previously reported series of roughly comparable patients managed without oxygen therapy, during 7-41 months of follow-up, these 33 chronically hypoxemic patients experienced 30-40\% reductions in mortality. ${ }^{57}$ However, demonstrating improved survival with LTOT to the standards of what eventually would be known as evidence-based medicine required much more deliberate, extensive study.

Definitive proof that LTOT extended life in appropriately selected patients with COPD was subsequently provided by the Nocturnal Oxygen Therapy Trial (NOTT), ${ }^{58}$ a federally sponsored multi-center study whose planning committee was chaired by Dr Petty, and by a similar study conducted in the United Kingdom. ${ }^{59}$ Numerous subsequent investigations of different aspects of LTOT have underscored the validity of the methodology and entry criteria of the NOTT, which became the foundation for current clinical use of LTOT. ${ }^{60,61}$

The dramatic effect of LTOT in reducing mortality among patients with severe COPD and chronic hypoxemia is shown in Figure 6, which compares the NOTT results in subjects under age 65 with the mortality rate in a multi- 


\section{Thomas L Petty's Lessons for the Respiratory Care Clinician of Today}

center trial of intermittent positive-pressure breathing for bronchodilator delivery in comparable subjects who did not have hypoxemia. ${ }^{62}$ That trial found no benefit from intermittent positive-pressure breathing compared with the non-pressurized administration of bronchodilators and also determined the 3-year mortality rate for patients with COPD managed comparably to the NOTT subjects except for LTOT. Figure 6 shows the excess hypoxemia-related mortality in such patients, represented by the NOTT subjects who used oxygen only at night, and its elimination with continuous oxygen therapy. ${ }^{62}$

One of the practical barriers to the appropriate use of oxygen in patients with COPD, both in and out of the hospital, was the prevalent belief among physicians that it would blunt the hypoxic respiratory drive and cause dangerous or even fatal $\mathrm{P}_{\mathrm{CO}_{2}}$ retention. As Dr Petty and his colleagues managed increasing numbers of patients with both hypoxemia and chronic hypercapnia, it became apparent to them that $\mathrm{P}_{\mathrm{aCO}}$ often did increase when hypoxemia was relieved but that this increase was modest and not life-threatening. To emphasize the safety of LTOT even in severely hypercapnic patients, they reported a series of 10 subjects with $\mathrm{P}_{\mathrm{aCO}}$ values exceeding $74 \mathrm{~mm} \mathrm{Hg}$ (range of 75-110 $\mathrm{mm} \mathrm{Hg}$ ) who were followed on oxygen as outpatients for a mean of 17 months. ${ }^{63}$ As to $\mathrm{CO}_{2}$ narcosis, the well-compensated subjects in this series demonstrated grossly normal central nervous system function, except for a fine tremor in some of them. ${ }^{63}$

From the very beginning of their experience with LTOT in Denver, Dr Petty's group incorporated ambulatory oxygen into the regimen. ${ }^{56}$ They obtained newly developed portable liquid units from the Linde Division of Union Carbide Corporation (Linde Walkers) and provided these to their patients, with the rationale that supplemental oxygen was most needed during exercise and that ambulatory oxygen would enable patients to do more. ${ }^{5}$ Dr Petty's strong advocacy of ambulatory oxygen therapy was an important aspect of his work in this field for the next 40 years. He felt that the fact that subjects on continuous oxygen therapy in the NOTT had substantially better survival than those getting it only at night was due in part to improved oxygenation during activities of daily living and maintenance of a greater degree of exercise. ${ }^{64}$

Particularly attuned to the practical difficulties encountered by his patients related to LTOT and aware that respiratory care relied heavily on medical devices and supplies, Dr Petty interacted closely with industry on several levels throughout his career. He carried out an evaluation of the first oxygen concentrator, ${ }^{5}$ and he subsequently performed studies on other oxygen-related devices, ventilators, and other apparatuses. ${ }^{6} \mathrm{He}$ believed that, in a technology-intensive field like respiratory care, it was important for researchers and clinicians to work closely with engi- neers and manufacturers to assure that new devices worked as they should from the patient's perspective.

As health care (and particularly home care) became ever more affected by reimbursement and regulatory matters, Dr Petty assumed an active role in addressing issues that affected patients' access to services and devices. He convened a series of oxygen consensus conferences that brought physicians and other health professionals together with manufacturers, suppliers, payers, government representatives, and patients to address the need for further research, educational issues related to the prescription and use of LTOT, problems of access and reimbursement, and other practical matters. ${ }^{65-70}$ Although these conferences and Dr Petty's involvement with industry did not endear him to some academics, I think there is little question that addressing the interdependence of the science, clinical delivery, and economic aspects of LTOT has benefitted respiratory care and its patients.

\section{Multidisciplinary, Patient-Focused Education and Training}

When I started working with Dr Petty as a first-year fellow in 1972, I got the impression that he knew every physician in Colorado. In fact, over the preceding 5 years, his multidisciplinary University of Colorado road show had visited virtually every hospital and clinic in the state, giving presentations and workshops on intensive respiratory care in both hospital and home settings. Many primary care physicians from around the region (and their nurses and other co-workers) had been to Denver for one of Dr Petty's many hands-on crash courses, covering such topics as intubation and mechanical ventilation, arterial blood gases, assessment of pulmonary function, and practical aspects of home oxygen therapy (Fig. 7). These things represented an enormous amount of time and energy and reflected 2 strongly held convictions: first, that respiratory care was a team activity that no single practitioner or specialty could carry out optimally, and second, that education and training could best benefit patients when targeted to the people who actually took care of them. These dual approaches to clinical education, which were described in several publications, ${ }^{71-73}$ epitomize Dr Petty's contributions to his field, and, as much as anything he did, justify his primacy as a historic figure in respiratory care.

Although available funding restricted the kinds of practitioners initially included in his rehabilitation program, Dr Petty recognized the need for a wider range of expertise in optimally managing a complex condition like COPD. He emphasized the importance of the primary care practitioner, usually a family physician, as the patient's main resource and thus the need for these practitioners to understand the disease and the different resources that might be called on. Although their services were not needed by 


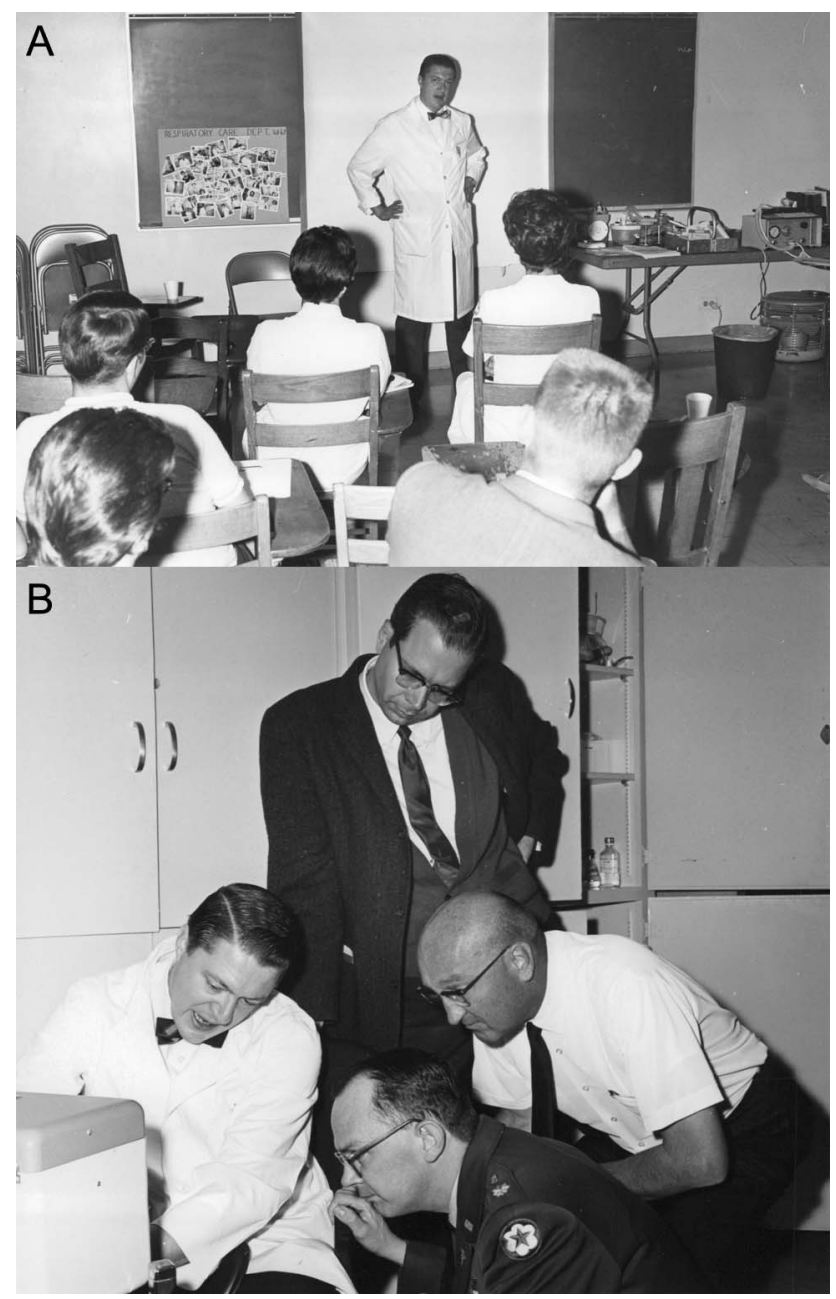

Fig. 7. Sessions at the University of Colorado for community physicians and other health-care workers in the late 1960s. A: Dr Petty in the classroom. B: Dr Petty demonstrates the operation of an early volume controlled ventilator during a hands-on workshop. Courtesy Louise M Nett.

every patient, in addition to pulmonologists, specially trained respiratory nurses, and RTs, the program also included physical therapists, nutritionists, social workers, psychiatrists, and psychologists. Representatives from each of these groups participated in the education programs coordinated by Dr Petty.

One aspect of Dr Petty's teaching that was not only unique for the time but also in fact revolutionary was the manner in which he presented it to the different professional groups involved. He believed strongly that it was not only the patient's doctor who needed to understand the mechanisms of disease and the rationale for treatment. For assessment and management to be rational, consistent, and properly carried out, the nurses and RTs had to understand these things, too. The care and detail with which he and his team instructed the non-physicians attending their sessions were comprehensive and unprecedented. In fact, a large

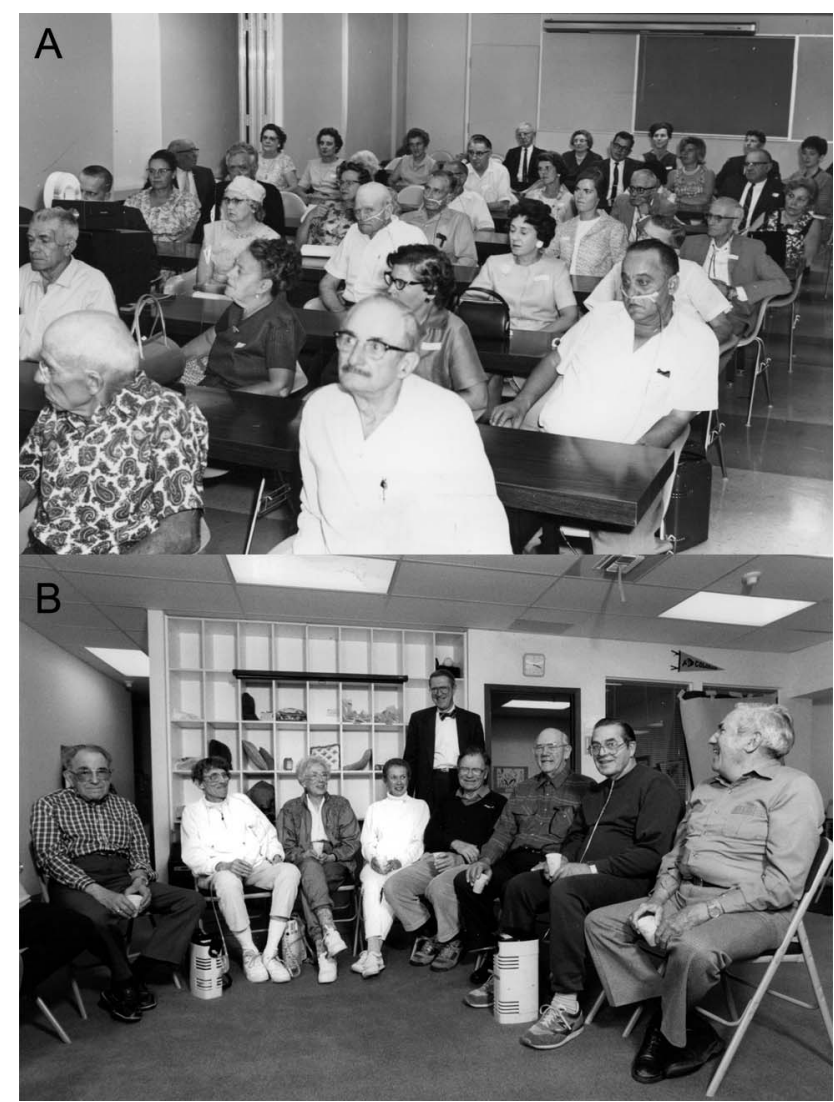

Fig. 8. A: A class for COPD patients and their family members in the late 1960s. B: Dr Petty with a Denver support group for patients with severe COPD. Courtesy Louise M Nett.

proportion of the educational content was presented in the same room, at the same time, to physicians and non-physicians alike.

Organized educational efforts emanating from Dr Petty's group beginning in the 1960 s included presentations and hands-on instructional sessions for patients and their caregivers, as well as for health-care workers (Fig. 8). With Louise Nett, Dr Petty published a series of books on COPD aimed at a lay readership, focusing not only on understanding the disease and its effects but also on practical aspects of living with it. ${ }^{18-22}$ Among the Frontline monographs he developed through the Snowdrift Pulmonary Conference, a 2002 volume directed at patients, written with James $\mathrm{T}$ Good $\mathrm{Jr}^{74}$ and available as a free download from Dr Petty's web site, ${ }^{15}$ remains the most sought-after publication in the series. Late in his life, Dr Petty maintained an impressive advocacy and educational productivity on behalf of patients with COPD and other chronic pulmonary conditions, adapting effectively to the evolution of educational venues and new media. ${ }^{17,23-28}$ 


\section{What Was So Special About Tom Petty?}

In the history of respiratory care, many individuals have made contributions that have advanced our current understanding and practice in important ways. Why, then, have I singled out Thomas L Petty as the most important physician in the history of the field and of the profession? It is because of a unique combination of charisma, intellectual curiosity, drive, insight, empathy, and hard work. I will list 6 manifestations of these characteristics that I think made him both special and truly unique.

First is his lifelong focus on common conditions that affect millions of patients and on aspects of their management that would benefit them the most. He acknowledged the importance of studying rare diseases or investigating basic mechanisms not obviously related to what he saw at the bedside or in the clinic. However, he believed that, as a clinician, he should focus his attention on what he encountered every day: acute respiratory failure and COPD, the bread and butter of respiratory care. Dr Petty's approach fit perfectly with some advice I first heard 30 years ago from my University of Washington colleague David Ralph: "When in Saudi Arabia, study sand." By devoting his research and practice energies to conditions he was confronted with every day, Dr Petty ended up directly and indirectly affecting the lives of millions of patients over the course of his long career.

Second, he understood the need for a collaborative, multidisciplinary team approach to patient care. As he wrote in his 1971 book, Intensive and Rehabilitative Respiratory Care, "The development of an organized team-approach for management of patients with acute respiratory failure has been a major advance of today's medicine and has provided the arena for systematic physiologically oriented care. The disciplines of internal medicine, surgery, anesthesiology, nursing care, inhalation therapy, and physical medicine and rehabilitation all come to bear on problems presented by each individual case." "(page v) Dr Petty empowered RTs and other non-physician clinicians to apply their specialized skills in managing conditions (whether acute respiratory failure or stable COPD) whose optimal management is not possible without such collaboration.

Third, as previously described, Dr Petty took his message to the people who needed it most: primary physicians, allied health professionals, patients, and their families.

Fourth, as I have also discussed, he appreciated the value of industry and maintained a respectful, collaborative interaction with its members. This facet of his work is not without controversy, yet he realized that respiratory care has a unique dependence on devices, apparatuses, and procedures, and he believed that benefit for patients could best be achieved if researchers, clinicians, inventors, manufacturers, and distributors of its technology worked together.

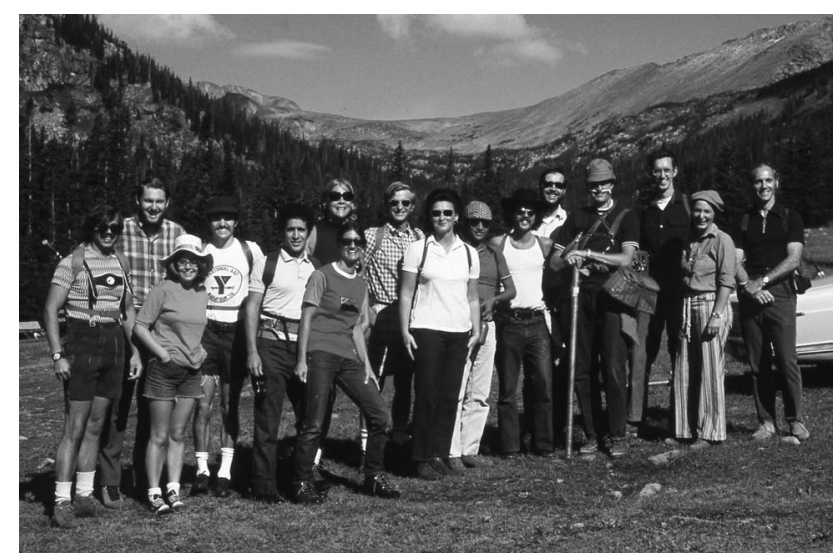

Fig. 9. Dr Petty (fourth from right), his fellows, and others at the start of the first annual Dorothy Lake hike in August 1972. Louise Nett is second from right, and the author is second from left. Dr Petty is outfitted with a portable liquid oxygen unit, which came in handy as the group ascended to the lake's 12,061-foot elevation. According to Louise Nett, his fishing creel, which carried trout on the way back, at this point contained beer.

Fifth, Dr Petty was truly interested in his patients as people. He cared deeply about them, and he always put their interests first. He exemplified the famous aphorism of Dr Francis Peabody, in a lecture to Harvard medical students in 1925: "One of the essential qualities of the clinician is interest in humanity, for the secret of the care of the patient is in caring for the patient." 75

Finally, he enjoyed his work and thought that others should, too. The first thing one learned on arriving in Denver to study with Dr Petty was that he worked incredibly hard and expected you also to do so. The second thing one learned was to be on time. When Dr Petty was on service, he started ICU rounds promptly at 7:30 each morning. As his fellow, arriving 5 or 10 minutes late and finding him already on the third patient was something one did only once: he did not say anything, but you knew. However, matching his drive for hard work was an equal drive to have a good time with one's workmates. Division meetings often included irreverence and hilarity of various kinds, and Dr Petty's after-work off-campus debriefings at local watering holes are treasured memories for those who trained with him in the early years.

In my era, one off-campus division activity that embodied Dr Petty's principle of having a good time was the pulmonary hike. Each summer, he would take the new fellows, their senior counterparts, and various others from the division on a hike to some scenic destination in the nearby Rockies, usually a destination involving fishing, Dr Petty's lifelong passion. For several years, the hike ascended to Dorothy Lake, high in the mountains, which sorely tested both the fitness and the resolve of his trainees, but the camaraderie was worth it (Fig. 9). 


\section{Thomas L Petty's Lessons for the Respiratory Care Clinician of Today}

Table 2. Thomas L Petty's Lessons for the Respiratory Care Clinician of Today (and Tomorrow)

(1) Whatever your role, you need to be an expert on the core, bread-and-butter areas of respiratory care:

Mechanical ventilation

ARDS

COPD

Oxygen therapy

(2) Everyone in respiratory care is a member of a team.

Each member of the team is vital, and no single team member can do it alone if our patients are to receive the best care.

The members of the team need to communicate and work together.

(3) Respiratory care education needs to be directed to those in the best position to benefit the patient.

(4) Clinicians, researchers, educators, and the respiratory care industry need each other, and each needs to appreciate the role of the others.

(5) It is all about the patient.

(6) Respiratory care is a noble and exciting profession, and doing it should be fun.

Speaking about what made him special in a 2009 obituary notice on the AARC's web site, Executive Director Sam Giordano said, "Dr Petty was a friend of all patients, especially to those with pulmonary diseases. 'Dr Tom,' as he was often referred to, was also a friend of those who cared for patients. Many physicians, nurses and respiratory therapists owe a great deal to him, not just because he spent countless hours helping us help our patients, but also because he continued to challenge and inspire us to do better." 76 Mr Giordano continued, pointing out that Dr Petty "has left us a magnificent legacy of service and support for our patients, as well as the challenge to put patients first and to search for ways to bring about more effective diagnosis and treatment. Even though he has received many accolades, awards and honors we somehow think that the best tribute to Dr Petty is that he was loved by his patients."

\section{What Lessons Do Tom Petty's Life and Work Offer for Today and the Future?}

In a rapidly changing world in which disease concepts and aspects of management considered state of the art just a few years ago are frequently dismissed as outmoded, much of Dr Petty's work from the 1960s and 1970s remains as correct and relevant today as when it was first reported. His enthusiasm, work ethic, and devotion to his patients and trainees continue to be examples for us all. I believe that 6 of Dr Petty's basic tenets, as presented here, stand as lessons for everyone entering respiratory care today and practicing it in the future. Table 2 summarizes these lessons, whose rationale and details I have discussed throughout this article.

\section{ACKNOWLEDGMENTS}

I thank Louise M Nett RN RRT FAARC for encouragement and for sharing her archive of photographs from Dr Petty's career, Catherine M Hough MD MSc for assistance with Figure 5, and Leonard D Hudson MD for his thorough and helpful review of the manuscript.

\section{REFERENCES}

1. Schwarz MI. Thomas L. Petty MD (1932-2009): a tribute. Am J Respir Crit Care Med 2010;181(5):425.

2. Iseman MD, Good JT Jr. Thomas L. Petty: extraordinary clinician, bold innovator, inspiring educator, loyal friend, world-class raconteur, and waltonesque angler. Chest 2010;137(6):1255-1256.

3. Richmond C. Thomas Lee Petty. [obituary] Lancet 2010;375(9725): 1520.

4. Pierson DJ. What is respiratory care? [editorial] Respir Care 1998; 43(1):17-19.

5. Petty TL. History of the University of Colorado Division of Pulmonary Sciences and Critical Care Medicine. Denver: Snowdrift Pulmonary Foundation; 2003.

6. Thomas L. Petty, M.D. Dec 24, 1932-Dec 12, 2009. http://www. drtompetty.org/short-biography. Accessed May 19, 2014.

7. Petty TL, editor. Intensive and rehabilitative respiratory care. Philadelphia: Lea \& Febiger; 1971.

8. Petty TL, editor. Pulmonary diagnostic techniques. Philadelphia: Lea \& Febiger; 1975.

9. Petty TL, editor. Chronic obstructive pulmonary disease. New York: Marcel Dekker; 1978.

10. Petty TL, editor. Chronic obstructive pulmonary disease, 2nd edition. New York: Marcel Dekker; 1985.

11. Casaburi R, Petty TL, editors. Principles and practice of pulmonary rehabilitation. Philadelphia: WB Saunders; 1993.

12. The Thomas L. Petty Aspen Lung Conference. About the conference-Program. http://www.aspenlungconference.org. Accessed May 19, 2014.

13. Petty TL. History of the Aspen Lung Conference. Denver: Snowdrift Pulmonary Conference; 2005.

14. Noehren TH, editor. Management of chronic obstructive diseases. United States Public Health Service Publication No. 1457. Washington, DC: United States Government Printing Office; 1967.

15. Snowdrift Pulmonary Conference, Inc. A not-for-profit 501c(3) corporation. http://www.drtompetty.org/snowdrift. Accessed May 19, 2014.

16. Murray JF, Petty TL, editors. Frontline treatment of COPD. Hackettstown, NJ: Snowdrift Pulmonary Conference; 1996.

17. Colorado Lung Health Connection. Thomas L Petty MD Moving Mountains Lung Health Conference. http://www.lunghealthco.org/ conference. Accessed May 19, 2014.

18. Petty TL, Nett LM. For those who live and breathe with emphysema and chronic bronchitis. Springfield, IL: Charles C Thomas Publisher; 1967.

19. Petty TL, Nett LM. For those who live and breathe: a manual for patients with emphysema and chronic bronchitis, 2nd edition. Springfield, IL: Charles C Thomas Publisher; 1975.

20. Petty TL, Nett LM. Enjoying life with emphysema. Philadelphia: Lea \& Febiger; 1984.

21. Petty TL, Nett LM. Enjoying life with emphysema, 2nd edition. Philadelphia: Lea \& Febiger; 1987.

22. Petty TL, Nett LM. Enjoying life with COPD, 3rd edition. Cedar Grove, NJ: Laennec Publishing; 1995.

23. Petty TL. Adventures of an oxy-phile. Irving, TX: American Association for Respiratory Care; 2004.

24. Petty TL. Adventures of an oxy-phile 2 . Denver: Snowdrift Pulmonary Conference; 2010. 


\section{Thomas L Petty's Lessons for the Respiratory Care Clinician of Today}

25. Petty TL, McCoy RW, Nett LM. Adventures of an oxy-phile 2 . http:// www.drtompetty.org/wp-content/uploads/2012/03/Adventures-ofan-Oxy-Phile-2.pdf. Accessed May 19, 2014.

26. Adventures of an oxy-phile ${ }_{2}$ : a free audio book by Dr. Thomas Petty. https://www.aarc.org/resources/oxyphile_audiobook. Accessed May 19, 2014.

27. Pulmonary Education and Research Foundation. Letters from Dr. Thomas Petty. http://www.perf2ndwind.org/tom/tom-petty-letterarchive.html. Accessed May 19, 2014.

28. Your Lung Health. Ask Dr. Tom archives. http://www.yourlung health.org/dr_tom/archive. Accessed May 19, 2014.

29. Petty TL. How it really happened. In the cards was ARDS (how we discovered the acute respiratory distress syndrome). Am J Respir Crit Care Med 2001;163(3 Pt 1):602-603.

30. Ashbaugh DG, Bigelow DB, Petty TL, Levine BE. Acute respiratory distress in adults. Lancet 1967;290(7511):319-323.

31. Ashbaugh DG, Petty TL, Bigelow DB, Harris TM. Continuous positive-pressure breathing (CPPB) in adult respiratory distress syndrome. J Thorac Cardiovasc Surg 1969;57(1):31-41.

32. Petty TL, Ashbaugh DG. The adult respiratory distress syndrome. Clinical features, factors influencing prognosis and principles of management. Chest 1971;60(3):233-239.

33. Petty TL, Nett LM, Ashbaugh DG. Improvement in oxygenation in the adult respiratory distress syndrome by positive end-expiratory pressure (PEEP). Respir Care 1971;16(2):173-176.

34. Lakshminarayan S, Stanford RE, Petty TL. Prognosis after recovery from adult respiratory distress syndrome. Am Rev Respir Dis 1976; 113(1):7-16.

35. Fowler AA, Hamman RF, Good JT Jr, Benson KN, Baird M, Eberle DJ, et al. Adult respiratory distress syndrome: risk with common predispositions. Ann Intern Med 1983;98(5 Pt 1):593-597.

36. Zwillich CW, Pierson DJ, Creagh CE, Sutton FD, Schatz E, Petty TL. Complications of assisted ventilation: a prospective study of 354 consecutive episodes. Am J Med 1974;57(2):161-170.

37. Stauffer JL, Olson DE, Petty TL. Complications and consequences of endotracheal intubation and tracheotomy. A prospective study of 150 critically ill adult patients. Am J Med 1981;70(1):65-76.

38. Sahn SA, Lakshminarayan S, Petty TL. Weaning from mechanical ventilation. JAMA 1976;235(20):2208-2212.

39. Sahn SA, Lakshminarayan S. Bedside criteria for discontinuation of mechanical ventilation. Chest 1973;63(6):1002-1005.

40. Bigelow DB, Petty TL, Ashbaugh DG, Levine BE, Nett LM, Tyler $\mathrm{SW}$. Acute respiratory failure. Experiences of a respiratory care unit. Med Clin North Am 1967;51(2):323-340.

41. Petty TL, Bigelow DB, Nett LM. The intensive respiratory care unit. An approach to the care of acute respiratory failure. Calif Med 1967;107(5):381-384

42. Petty TL, Farrington JF. The intensive respiratory care unit. Clin Notes Respir Dis 1971;10(1):3-11.

43. Petty TL, Dulfano MJ, Singer M, Webb WR. Essentials of an intensive respiratory care unit. Report of the Subcommittee and Committee on Emphysema American College of Chest Physicians. Chest 1971;59(5):554-556.

44. Petty TL, Lakshminarayan S, Sahn SA, Zwillich CW, Nett LM. Intensive respiratory care unit. Review of ten years' experience. JAMA 1975;233(1):34-37.

45. Petty TL. Answers to questions on acute respiratory failure. Hosp Med 1970;6:36-45.

46. Petty TL. Suspended life or extending death? [editorial] Chest 1998; 114(2):360-361.

47. Tyler ML, Nett LM. Intensive nursing and respiratory therapy. In: Petty TL, editor. Intensive and rehabilitative respiratory care, 2nd edition. Philadelphia: Lea \& Febiger; 1974:79-98.
48. Petty TL, Nett LM, Finigan MM, Brink GA, Corsello PR. A comprehensive care program for chronic airway obstruction: methods and preliminary evaluation of symptomatic and functional improvement. Ann Intern Med 1969;70(6):1109-1120.

49. Sahn SA, Pierson DJ, Petty TL, Lakshminarayan S. [Rehabilitation of patients with severe chronic obstruction of the respiratory tract: 8-year follow-up study of 182 patients]. Bull Int Union Tuberc 1976; 51(1 Pt 2):713-716. Article in French.

50. Sahn SA, Nett LM, Petty TL. Ten-year follow-up of a comprehensive rehabilitation program for severe COPD. Chest 1980;77(2 Suppl): 311-314.

51. Hudson LD, Tyler ML, Petty TL. Hospitalization needs during an outpatient rehabilitation program for severe chronic airway obstruction. Chest 1976;70(5):606-610.

52. Petty TL, MacIlroy ER, Swigert MA, Brink GA. Chronic airway obstruction, respiratory insufficiency, and gainful employment. Arch Environ Health 1970;21(1):71-78.

53. Spruit MA, Singh SJ, Garvey C, ZuWallack R, Nici L, Rochester C, et al. An official American Thoracic Society/European Respiratory Society statement: key concepts and advances in pulmonary rehabilitation. Am J Respir Crit Care Med 2013;188(8):e13-e64.

54. Petty TL, Bigelow DB, Levine BE. The simplicity and safety of arterial puncture. JAMA 1966;195(8):693-695.

55. Levine BE, Bigelow DB, Hamstra RD, Beckwitt HJ, Mitchell RS, Nett LM, et al. The role of long-term continuous oxygen administration in patients with chronic airway obstruction with hypoxemia. Ann Intern Med 1967;66(4):639-650.

56. Petty TL, Finigan MM. Clinical evaluation of prolonged ambulatory oxygen therapy in chronic airway obstruction. Am J Med 1968; 45(2):242-252.

57. Neff TA, Petty TL. Long-term continuous oxygen therapy in chronic airway obstruction. Mortality in relationship to cor pulmonale, hypoxia, and hypercapnia. Ann Intern Med 1970;72(5):621-626.

58. Nocturnal Oxygen Therapy Trial Group. Continuous or nocturnal oxygen therapy in hypoxemic chronic obstructive lung disease: a clinical trial. Ann Intern Med 1980;93(3):391-398.

59. Report of the Medical Research Council Working Party. Long term domiciliary oxygen therapy in chronic hypoxic cor pulmonale complicating chronic bronchitis and emphysema. Lancet 1981;317(8222): 681-686.

60. Petty TL. Historical highlights of long-term oxygen therapy. Respir Care 2000;45(1):29-36; discussion 36-38.

61. Pierson DJ. Oxygen in respiratory care: a personal perspective from 40 years in the field. Respir Care 2013;58(1):196-204.

62. Anthonisen NR, Wright EC, Hodgkin JE. Prognosis in chronic obstructive pulmonary disease. Am Rev Respir Dis 1986;133(1):14-20.

63. Neff TA, Petty TL. Tolerance and survival in severe chronic hypercapnia. Arch Intern Med 1972;129(4):591-596.

64. Petty TL, Bliss PL. Ambulatory oxygen therapy, exercise, and survival with advanced chronic obstructive pulmonary disease (The Nocturnal Oxygen Therapy Trial revisited). Respir Care 2000;45(2): 204-211; discussion 211-213.

65. Petty, TL. Problems in prescribing and supplying oxygen for Medicare patients. Am Rev Respir Dis 1986;134(2):340-341.

66. Further recommendations for prescribing and supplying long-term oxygen therapy (summary of the Second Conference on Long-Term Oxygen Therapy held in Denver, Colorado, December 11-12, 1987). Am Rev Respir Dis 1988;138(3):745-747.

67. New problems in supply, reimbursement, and certification of medical necessity for long-term oxygen therapy (summary of the Third Consensus Conference held in Washington, DC, March 15-16, 1990). Am Rev Respir Dis 1990;142(3):721-724.

68. Petty TL, O'Donohue WJ Jr. Further recommendations for prescribing, reimbursement, technology development, and research in long- 


\section{Thomas L Petty's Lessons for the Respiratory Care Clinician of Today}

term oxygen therapy (summary of the Fourth Oxygen Consensus Conference, held in Washington, DC, October 15-16, 1993). Am J Respir Crit Care Med 1994;150(3):875-877.

69. Petty TL, Casaburi R. Recommendations of the Fifth Oxygen Consensus Conference. Writing and Organizing Committees. Respir Care 2000;45(8):957-961.

70. Doherty DE, Petty TL, Bailey W, Carlin B, Cassaburi R, Christopher $\mathrm{K}$, et al. Recommendations of the 6th Long-Term Oxygen Therapy Consensus Conference. Respir Care 2006;51(5):519-525.

71. Petty TL, Nett LM, Bigelow DB, Ashbaugh DG. The management of acute and chronic respiratory insufficiency. A one-week training course. Arch Environ Health 1968;17(3):398-402.
72. Farrington JF, Mattusch L, Petty TL. Comprehensive respiratory care in the small community hospital? Yes, it can be done. Bull Natl Tuberc Respir Dis Assoc 1971;57(5):11-13.

73. Petty TL, Neff TA, Nett LM, Tyler ML. A program for community training in respiratory care. Chest 1973;64(5):636-640.

74. Good JT Jr, Petty TL. Frontline advice for COPD patients. Denver: Snowdrift Pulmonary Conference; 2002.

75. Peabody FW. The care of the patient. JAMA 1927;88(12):877882.

76. American Association for Respiratory Care. In the news: pulmonary community loses pioneering physician: December 14, 2009. http:// www.aarc.org/headlines/09/12/petty. Accessed May 19, 2014. 